\title{
El discurso en la mirada: Los Españoles y la visión del Tawantinsuyo
}

\author{
Martha Barriga Tello \\ Universidad Nacional Mayor de San Marcos \\ martha_barriga@yahoo.com.ar
}

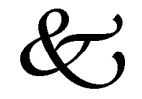

\begin{abstract}
Resumen
El estudio ofrece las diversas lecturas de los monumentos del Imperio Inca realizadas por los primeros españoles. Sus apreciaciones varían de acuerdo a su experiencia previa, sus conocimientos y aquello con que les era posible compararlos. La primera impresión quedará como eje para las opiniones que posteriormente ofrecerán en sus escritos.

Palabras claves: Arquitectura inca, Cronistas españoles, Relación Xámano-Jerez.
\end{abstract}

\begin{abstract}
This article studies the first view of the Empire of the Incas monuments by the first spanish men. Their apreciation differ in relation with their previous experiences, knowledge and what they were able to compare with. The first sight will remain as a reference for further opinions in their documents.
\end{abstract}

Key words: Inca architecture, Spanish chroniclers, Relation XámanoJerez. 


\section{PRIMEROS EUROPEOS EN EL PERÚ}

Las crónicas españolas de la primera mitad del siglo XVI en el Perú permiten abordar la relación entre europeos y americanos desde el condicionamiento que guió el lenguaje utilizado en sus descripciones, la verbalización a partir de sus experiencias visuales. Los españoles que entraron en Cajamarca llegaban inmersos en los rumores que circulaban en Panamá sobre las riquezas que existían hacia el sur. Creyeron ver confirmadas sus aspiraciones en lo que se halló en el navío de Tumbes, descrita en la Relación Xámano - Jeréz de 1533, "madexas de hillo de oro que pesaba más de seiscientos castellanos” (Relación 1967:64). El mismo año se consigna que muchos de los expedicionarios escribieron

a sus compañeros que se vayan e desamparen sus haziendas o que las den a quien quisieren que lo de allí [Perú] es tanto que no han menester cosa de lo que acá tienen e que aquella tierra es la viña de Dios y otras muy grandes cosas que en verdad ahun para desbarío parece grande: la plata tienen en corral porque no saven donde la echar (Espinosa 1967:39).

Gaspar de Espinosa consideró que tanta abundancia era la ayuda que ofrecía Dios a Carlos V para que "con más ánimo e possibilidad prosiga la sancta empresa e guerra contra el turco e luterio y los otros enemigos de la fee" (Espinosa, 1967:39), meta que dominaba como prioritaria. Con informaciones y proyectos tales, los expedicionarios tuvieron como objetivo inmediato todo material valioso, respaldando y justificando sus acciones en que combatían infieles en tanto obtenían territorios para la corona.

Don Alonso Enríquez de Guzmán, en su Libro de la vida y costumbres de ... caballero desbaratado, escrito por él mismo (1550), mostró admiración por las casas de Tumbes que vio en su viaje al Perú en 1535. Las describe "labradas las paredes de adobes a manera de ladrillo y con muchas colores muy finas pintadas y barnizadas, que nunca vi cosa más linda, la techumbre de paja también labrada, que no parece syno de oro, muy fuerte e muy grand e muy hermosa" (Enríquez 1960: 147), un aspecto que fue corroborado por otras fuentes.

Pero también fueron encontrando monumentos de valor y condición distinta, más cercana a su experiencia. Se impresionaron por las construcciones militares que se hallaron a medida que penetraban en el te- 
rritorio peruano. Camino a Cajamarca, el grupo de españoles que acompañaba a Francisco Pizarro avanzaba cautelosamente atisbando posibles lugares de ataque indígena, como la "fortaleza cercada encima de una sierra en un mal paso", y a la que solamente era posible acceder por escaleras en determinados lugares porque "no había otra parte por do subir sino sólo por aquel camino” (Jerez 1968: 217). La fortaleza debió ser rodeada y explorada por los soldados. Francisco de Jerez se interesó especialmente por su arquitectura, la que encontró: "fuerte, cercada de piedra y labrada de cantería, tan ancha la cerca como cualquier fortaleza de España con sus puertas; que si en esta tierra hobiese maestros y herramientas de España no pudiera ser mejor labrada la cerca" (Jerez, 1968: 218). El cronista la compara con su referente europeo y adelanta un juicio de valor apreciando la calidad de la cantería y asombrándose de su edificación "como cualquier fortaleza de España". Sin embargo sabemos que, a pesar de disponer de ambos elementos, y ya perdido el poder indígena, en el Perú no volvió a repetirse una arquitectura de la magnitud de la vista. La administración virreinal no tuvo necesidad de construir edificios-fortaleza civiles, religiosos ni militares, como en otros lugares americanos.

No fue menor la opinión de Jerez acerca de la plaza de Cajamarca, que consideró "mayor que ninguna de España, toda cercada con dos puertas, que salen a las calles del pueblo" (Jerez 1968: 222). Según Pedro Cieza de León, una muralla cercaba los aposentos reales y la plaza tenía forma rectangular (Cieza de León III 1989: Cap. XLII). Acerca de la arquitectura que la rodeaba, añadió Francisco de Jerez,

Las casas della son de más de doscientos pasos de largo, son muy bien hechas, cercadas de tapias fuertes, de altura de tres estados; las paredes y el techo cubierto de paja y madera asentada sobre las paredes; están dentro destas casas unos aposentos repartidos en ocho cuartos muy mejor hechos que ninguno de los otros. Las paredes dellos son de cantería muy bien labrada, y cercados estos aposentos por sí con una cerca de cantería y sus puertas, y dentro en los patios sus pilas de agua traída de otra parte por caños para el servicio destas casas (Jerez 1968: 123).

Jerez es, entre los cronistas iniciales, quien parece estar mejor dispuesto a la observación aparentemente directa y desprejuiciada de las ciudades indígenas, su organización y el conjunto urbano, tal como lo demuestra su descripción de los alrededores de la plaza de Cajamarca, 
...por la delantera desta plaza, a la parte del campo, está incorporada en la plaza una fortaleza de piedra con una escalera de cantería, por donde suben de la plaza a la fortaleza, por la delantera della, a la parte del campo, está otra puerta falsa pequeña, con otra escalera angosta, sin salir de la cerca de la plaza. Sobre este pueblo, en la ladera de la sierra, donde comienzan las casas dél, está otra fortaleza asentada en un peñol, la mayor parte dél tajado. Esta es mayor que la otra, cercada de tres cercas, flecha subida como caracol ... entre la sierra y esta plaza grande, está otra plaza más pequeña, cercada toda de aposentos. Y antes de entrar en este pueblo hay una casa cercada de un corral de tapia, y en él una arboleda puesta a mano. Esta casa dicen que es del sol porque en cada pueblo hacen sus mezquitas al sol (Jerez, 1968: 223)

No era lo único, porque "otras mezquitas hay en este pueblo, y en toda esta tierra las tienen en veneración, y cuando entran en ellas se quitan los zapatos a la puerta" (Jerez 1968: 223). Este cronista es bastante preciso cuando señala aspectos urbanísticos y arquitectónicos, aunque su experiencia debió desprenderse de su actividad militar. Tal como se aprecia, al final de la descripción la denominación "mezquita" referida al templo, retrotrae su percepción al paralelismo con el simbolismo hispano del monumento musulmán, expresión de un pueblo opositor. Puede haber utilizado el recurso para hacer más precisa su descripción en la percepción del receptor, tanto en el nivel de reconstrucción formal como connotativa.

La condición del soldado también es importante para comprender su capacidad de acercamiento al objeto. Para Hernando Pizarro la edificación que impresionó a Jerez, y que no se detiene a describir, era "una fortalecilla", a la que prestó atención exclusivamente porque en ella se colocaron algunos indios con "una bandera puesta en una lanza” (Pizarro 1968:123). Cristóbal de Mena mencionó los edificios de la plaza en los que Francisco Pizarro y sus hombres se guarecieron como "tres casas muy grandes, que tenía cada una doscientos pasos y veynte puertas" y "una fortaleza muy fuerte" en medio de la plaza (Mena 1967: 85). No agrega ningún otro dato. Cristóbal de Mena no es exclusivamente parco, sino indiferente a todo aquello que no lo involucrara directamente. Su preocupación se concentra en la estrategia militar, lo máximo que menciona es la "fortaleza cercada" camino a Cajamarca, que Pizarro desestimó como albergue para usar otra situada más adelante, "una casa fuerte de cal y canto", que pertenecía al Señor (Mena 
1967: 82). Cuando, en medio de una granizada, encontraron el Real de Atahualpa lo describieron como "una casa cercada de árboles, al derredor de aquella casa a cada parte estaba cubierto de toldos blancos más de media legua" (Mena 1967: 83). El espectáculo impresionó a los españoles por su magnitud y la posibilidad que pudiera albergar gran cantidad de hombres de guerra.

La preocupación por las estructuras arquitectónicas se manifiesta nuevamente en Francisco de Jerez. Consideró estos aposentos de Atahualpa como los mejores que hasta el momento había visto, con cuatro habitaciones rodeando un patio, en el que se abría un estanque de piedra con agua caliente y fría. El destinado a Atahualpa lo describió como una habitación con una logia sobre un huerto, cuyas paredes estaban pintadas de un rojo al que denomina "bermejo", color que también tenían las maderas del techo. Describe otra habitación extrañamente la cubierta con "cuatro bóvedas, redondas como campanas, todas cuatro incorporadas en una”, pintadas de blanco "como nieve" (Jerez 1968: 234). Este tipo de cubierta no está consignada entre las utilizadas en el Perú antiguo. De ser justa la apreciación del cronista, la techumbre habría tenido la apariencia de una bóveda de crucería, un elemento que no se consigna en la arquitectura peruana antigua. Sin embargo, existen antecedentes de bóvedas falsas semicirculares, única posibilidad que cabe en este caso. Su construcción supone el adelantamiento progresivo de cada una de las hiladas en el paramento, hasta lograr su confluencia en la zona de la clave, esto es el cierre central superior. La alusión a "campanas", probablemente por su aspecto ligeramente cónico, permite identificar este recurso, por otra parte muy utilizado por muchas de la culturas antiguas.

Cuando señaló pormenorizadamente el navío de Tumbes también demostró Jerez especial habilidad como observador. Apreció su tonelaje, su hechura que describió "con cañas tan gruesas como postes ligados por sogas de unos que dicen henequén que es como cáñamo y los altos de otras cañas más delgadas ... de muy fina madera y velas de algodón del mismo talle de manera que los nuestros navíos" (Relación Xámano - Jerez 1967: 66). Además, pudo describir la orfebrería fina, espejos, vajilla y textiles, algunos de los que identifica con las túnicas de mangas cortas moriscas llamadas "aljubas", y con los pantalones cortos, 
también moriscos, llamados "alaremes”. Igualmente señaló que para comerciar "traían unos pesos chiquitos de pesar oro como hechura de romana” (Relación Xámano - Jerez 1967: 66). Jerez transmite la imagen de un individuo de carácter calmado y reflexivo, con suficiente experiencia como para reparar en detalles que no se impusieron a su percepción por su novedad. Detalla y explica como si trazara un dibujo, se detiene en aspectos que contribuyen a recomponer su mirada al receptor oficial, enalteciendo paralelamente la campaña que hizo posible la experiencia.

Es la transmisión de estas imágenes, condicionadas por el conocimiento personal y el colectivo de los receptores, que dirige la reconstrucción europea de algunas escenas. En la edición de la crónica de Cristóbal de Mena realizada en París, 1545 se incluyó un mapa con figuras e inscripciones que Raúl Porras consideró el primer documento cartográfico del Perú, en el que aparecía: "Un templo de corte románico" que llevaba la leyenda, en francés,: "La mezquita del Sol toda cubierta de oro", y debajo un dibujo de una ciudad bizantina con minaretes y cúpulas que pretendía simular la pirámide de Pachacámac en la que estaba inscrito "Pachalchami, ciudad más grande que París" (trad. nuestra).

Un grabado de características similares apareció en la edición de 1547 impresa en Salamanca de la Verdadera historia de la conquista del Perú y la provincia del Cuzco llamada Nueva Castilla de Francisco de Jeréz (Vargas Ugarte, 1981: Lám. XI). Como se conoce, los informes de Cristóbal de Mena y de Francisco de Jerez buscaron aclararse mutuamente respecto a la acción de los participantes en la campaña de Francisco Pizarro, pero sus ediciones compartieron la imagen central con la representación de la escena del requerimiento seleccionada por los editores. El intentar la reconstrucción de las descripciones de los cronistas iniciales orientó el imaginario europeo, no solamente el español, que erró en los motivos que pretendieron explicar lo que la crónica ofrecía. Actualmente nos informa sobre el referente específico, que igualmente debió conducir la visión del cronista, vinculado a una mentalidad asociada todavía a lo maravilloso y heroico en el sentido medieval. 
Ampliando la exploración, Hernando Pizarro llegó a Pachacámac en 1533 para ver la “mezquita” (Pizarro 1968:125), que les habían informado que tenía mucho oro (Pizarro 1968:91), especialmente por la gran devoción que se le profesaba y siguió manteniendo, en todo el territorio que recorrían (Cieza de León I 1947: II). Pizarro la describió conformada por un primer patio bajo y otro en un segundo nivel, en el que encontró "una camarilla, donde dicen que hablan con él [ diablo]" (Cieza de León 1947), la misma que luego denomina "cueva" porque era muy oscura y "muy sucia”. Los españoles debieron ingresar valiéndose de antorchas. Mena coincide con esta escueta descripción (Mena 1968: 94). Miguel de Estete, que formó parte del equipo de Hernando Pizarro, mostró mayor interés e hizo una detallada mención de la edificación,

nos llevaron, pasando muchas puertas hasta llegar hasta la cumbre de la mezquita, la cual era cercada de tres o cuatro cercas ciegas, a manera de caracol; y así se subía a ella...En lo alto estaba un patio pequeño delante de la bóveda o cueba (sic) del ídolo, hecho de ramada con unos postes guarnecidos de hoja de oro y plata, y en el techo puestas ciertas tejeduras, a manera de estera para la defensa del sol...pasando el patio estaba una puerta cerrada y en ella las guardas acostumbradas...Esta puerta era muy tejida de diversas cosas; de corales y turquesas y cristales y otras cosas. Finalmente que ella se abrió y según la puerta era curiosa, así tuvimos por cierto que había de ser lo de dentro; lo cual fue muy al revés y bien pareció ser aposento del diablo, que siempre se aposenta en lugares sucios...apenas cabía un hombre, y había mucha oscuridad ... una cueva muy pequeña, tosca, sin ninguna labor; y en medio de ella estaba un madero hincado en la tierra con una figura de hombre hecha en la cabeza de él, mal tallada y mal formada, y al pie, a la redonda del muchas cosillas de oro y plata (Estete 1968: 383).

Aquí observamos interesantes aspectos. Estete permite que el lector comparta su recorrido por el recinto a medida que es conducido, observando y transmitiendo detalles que le confirmen la fama del lugar. Cuando llega a la cámara central, objeto de su anhelo, se incomodó por la dimensión y apariencia del lugar, por la oscuridad y por el radical contraste con las puertas, que le habían hecho suponer un magnífico interior. Años después Pedro de la Gasca afirmó haber visitado este mismo "gran templo o edificio junto a la mar, que aún hoy día parece de mucha magestad (dado que está arruinado)". Gasca subió al templo y, 
efectivamente, encontró una cámara muy oscura y afirma que vio "todas las paredes pintadas de diversidad de animales así de tierra como de mar" (Gasca1998: 30). De acuerdo a las informaciones que había recibido, interpretó que eran personificaciones del dios Pachacámac. Por la misma época Pedro Cieza de León mencionó que en el templo "había muchas puertas pintadas ellas y las paredes con figuras de animales fieros" (Cieza 1947: Cap. LXXII). A principio del siglo XVII Bernabé Cobo señaló que las puertas estaban llenas de varias pinturas "a cada vuelta", y que: "las paredes estaban enlucidas de tierra y pintura de varios colores, con muchas labores curiosas a su modo, si bien al nuestro toscas y diversas figuras de animales mal formadas, como todo lo que los indios pintaron" (Cobo 1956: II, Libro 13, Cap. XVII).

En este ejemplo puede contrastarse las alteraciones que pueden resultar de la circunstancia del individuo que describe. Miguel de Estete, que ingresó antes y detalló el aspecto rico de las puertas, no vio las pinturas o, de haberlas visto, no les prestó la atención que dio a los exvotos en el suelo. Su percepción, siendo más acuciosa que la de sus compañeros, obvió este detalle que, además, no solamente aparecía en la cámara del templo, sino que cubría otras puertas y muros. La falta de correlación entre la riqueza de la puerta y la del interior del recinto, auspiciada por la información previa, frustró lo que esperó encontrar en Pachacamac, lo que supuso una doble decepción reflejada en su reacción al encontrar un lugar que en nada condecía con su exterior. Su percepción estuvo condicionada por la información previa que generó expectativas de opulencia, lo que le impidió notar cualquier cosa ajena a esta preocupación. Los que visitaron el templo posteriormente no mostraron sino curiosidad, lo que les permitió señalar detalles anteriormente no significativos. Para evaluar los datos en las crónicas es importante tener en consideración la importancia que cada experiencia tuvo para los actores en el momento que se estudia. Por la condición e interés de los narradores, los textos se complementan en la reconstrucción de las imágenes.

Una referencia importante en los cronistas, porque no se encuentran hoy día restos suficientes en la costa, fue el Camino Real, que admiraron todos. Miguel de Estete fue explícito sobre las pinturas que cubrían sus muros. Estete, que no vio pinturas en Pachacamac, nos cuenta que 
recorrió un bien estructurado camino Inca, plantado de árboles "que se juntan arriba y hacen sombra”, y que donde éstos faltaban "van paredes hechas de una parte y otra, y en ellas pinturas de monstruos y pescados, y otros animales, para que mirándoles pasen el tiempo los caminantes" (Estete 1968: 395). En esta oportunidad pudo observar las imágenes pintadas e interpretar que tenían la finalidad que él les dio en el trayecto. En la zona andina el camino era una "calzada ancha y fuerte de cantería” (Cieza 1947 Cap. XCVII) del que se cuenta que Hernando de Soto "se espantó contemplando el modo con que yba hecho" (Cieza, 1947 Cap. XXXVIII). El camino fue comparado, tanto por su construcción como por su extensión, con las vías romanas que atravesaban Europa y que en gran parte comunicaban el continente, tal como sucedía en el Tawantinsuyo.

Respecto a la pintura mural que pudieron observar los españoles no se puede rescatar mucho en los textos. De los primeros españoles, Miguel de Estete estuvo entre los que tuvieron en parte la sensibilidad para observarla y transmitir el aspecto de esta extendida práctica en el arte peruano antiguo. Anteriormente describió el templo dedicado al Sol en Tumbes como un edificio que "era cosa de ver" porque, además de tener una dimensión considerable, estaba "todo él por dentro y por fuera pintado de grandes pinturas y ricos matices de colores, porque los hay en aquella tierra (Estete 1968: 364), un aspecto que fue también señalado por Alonso Enríquez. Ambas descripciones son un valioso documento para reconstruir el orden de sus percepciones. Enríquez de Guzmán añadió que "agora los cristianos, como digo, tienen hechas casas de tierra, hechas de adobes pintados, y cobertizadas, como en Castilla, y buenas huertas dentro ellas" (Enríquez de Guzmán1960: 148). La diferencia con las indígenas era el barniz, o cubierta de protección sobre los muros. Los colores que predominaban fueron blanco, rojo, negro, amarillo. Menos frecuentes el verde y el azul del lapislázuli o sodalita, que aún comerciaban los indios en el virreinato. Estete se mostró capaz de distinguir matices en las combinaciones de color cuando los encontró in situ, e igualmente observó diversas calidades y matices al señalar "porque los hay en aquella tierra”. De acuerdo al testimonio de Enríquez de Guzmán, los españoles trasladaron sus técnicas arquitectónicas y decorativas "como en Castilla", aunque adoptaron los adobes cubiertos de 
pintura a la manera indígena. Igualmente el uso del barniz comenzó a ser utilizado por los indígenas para cubrir piezas de cerámica pertenecientes a la etapa de transición. Respecto a las edificaciones en la costa recalca Cieza que los españoles siguieron la técnica constructiva usada en la zona para las cubiertas de sus casas, "En este tiempo se hace así, y los españoles, en sus casas, no usan otros tejados que estas esteras embarradas" (Cieza 1947: Cap. XXXVI).Esta fue una época en la que, como resultado de la curiosidad por una parte y de la respuesta al medio por otra, interactuaron europeos y americanos, porque aprovecharon las técnicas útiles a la circunstancia. Este enriquecimiento contribuyó a las características peculiares del arte producido durante el virreinato en el Perú, el que es sufragáneo tanto de España como de los pueblos que formaron el Tawantinsuyo.

Otra interesante comparación respecto a observaciones complementarias, nos permite la descripción que hizo Estete de la fortaleza de Paramonga, "tiene una casa fuerte con cinco cercas ciegas, pintadas de muchas labores por de dentro y por de fuera, con sus portadas bien labradas a la manera de España, con dos tigres a la puerta principal" (Estete 1968: 246). Una referencia paralela consignó Pedro Cieza de León quien admitió lo bien trazada que estaba la fortaleza, "al uso de los que la edificaron", reconociendo que estaba hecha según normas y planteamientos diferentes a los españoles. Añadió, "Las moradas y aposentos eran muy galanos, y tienen por las paredes pintados muchos animales fieros y pájaros cercada toda de fuertes paredes y bien obrada; ya está toda muy ruinada" (Cieza de León 1947: Cap. LXX). Las mismas características decorativas encontró en la fortaleza de piedra del valle de Guarco, que también describió como "adornada de pinturas". Pedro Sancho, el otro escribano de Francisco Pizarro, señaló que las casas de los señores incas en el Cusco, "son las principales de la ciudad, pintadas y labradas y de piedra”. Sobre la casa que identifica como de Huayna Capac observó otro tipo de decoración pictórica, "y la puerta es de mármol blanco y encarnado y de otros colores" (Sancho 1968: Cap. XVII). En la crónica de Miguel de Estete la casa del Señor del Cusco es descrita con "una portada rica chapada de piezas de plata y de otros metales" y que “parecían bien” (Estete 1968: 392). 
En estos y otros casos, cuando los cronistas se refieren a "pintura" están mencionando muros policromados pero, según las mismas fuentes, no fue la única fórmula ornamental pues existió la costumbre de otro tipo de adorno parietal. Pedro Cieza de León describió en el actual territorio de Ecuador edificios en los que "en algunas paredes destos aposentos se ve bien claro donde estaban escajadas las ovejas de oro y otras grandezas que esculpían en las paredes. Especialmente había esta riqueza en el aposento que estaba señalado para los reyes ingas, y en el templo del sol" (Cieza de León 1947: Cap. XLI), y otro tanto en Tumebamba, al norte del Perú,

Las portadas de muchos aposentos estaban galanas y muy pintadas y en ellas asentadas algunas piedras preciosas y esmeraldas, y en lo de dentro estaban las paredes del templo del Sol y los palacios de los reyes ingas, chapados de finísimo oro y entalladas muchas figuras, lo cual estaba hecho todo lo más deste metal y muy fino (Cieza, 1947: Cap. LXIV).

Bernabé Cobo recogió la información de que las "salas y aposentos [del Inca estaban] adornados con riquezas extrañas. Víanse por las paredes esculpidas diversas figuras de oro puro de animales, aves y de otras cosas a este modo" (Cobo 1956: Libro 12, Cap. XXXVI). La escultura adosada y/o los relieves en los recintos constituyó un elemento sorprendente para los españoles, no por la técnica, que en España era frecuente, sino por el material con el que estaban trabajadas. La otra reflexión respecto al informe de los cronistas es la importancia del color en la arquitectura del Tawantinsuyo. Por lo que describen los cronistas, por lo menos para la costa, y comprueban los restos arqueológicos en diversas zonas del Perú correspondientes a distintas épocas, los muros estaban enlucidos y policromados pues aún puede observarse vestigios de pintura, en ocasiones representativa y en otras parietal uniforme.

Las experiencias que recibían los españoles hizo que intentaran explicarse la condición magnífica de las obras, tanto de arquitectura como de artes plásticas, que encontraban conforme se adentraban en el territorio del Imperio de los Incas. En un momento de su viaje Pedro Cieza de León llegó a Huamanga, en Ayacucho. Allí le contaron una sorprendente historia que justificaba la excelencia de los edificios que vio, para él inadecuadas e imposibles como creación de indios. Encontró una explicación plausible de acuerdo a algunas de las concepciones que 
imaginaban los españoles para el Imperio. Observó en el río Vinaque una fortaleza y,

Preguntando a los indios comarcanos quien hizo aquellas antiguallas responden que otras gentes barbadas y blancas como nosotros, los cuales muchos tiempos antes que los ingas reinasen, dicen que vinieron a estas partes e hicieron allí su morada, y desto y de otros edificios antiguos que hay en este reino me parece que no son la traza dellos como los que los indios hicieron o mandaron hacer. Porque este edificio era cuadrado, y los de los ingas largos y angostos. Y también hay fama que se hallaron ciertas letras en una losa deste edificio, lo cual ni lo afirmo ni dejo de tener para mi que en tiempos pasados hubiese llegado aquí alguna gente de tal juicio y razón que hiciesen estas cosas y otras que no vemos (Cieza 1947: Cap. LXXXVII).

Al respecto destacaremos varios puntos importantes por ser emitidos por un cronista de la calidad de Pedro Cieza de León, siempre cauto y justo en sus apreciaciones, aunque no por ello menos condicionado. En primer lugar hay que tener muy en cuenta que el emisor, según el cronista, fue indígena. Desde el lado del cronista, incluir esta explicación expresaría que, no solamente estaba siendo utilizada y difundida por la comunidad indígena como discurso, sino que la aceptó porque debió cumplir la función de razón compensatoria. Por un lado se explicaba que una raza superior, diferente a la encontrada en el país pero similar a la suya, había levantado los edificios e igualmente significaba que no eran los peruanos fundadores ni propietarios del sitio ni de los edificios. Además, la condición de las estructuras le permite afirmar que pertenecieron a gente "de tal juicio y razón que hiciera estas cosas y otras que no vemos”. Al ampliar el ámbito de asuntos vinculados a la calidad de los edificios agrega el elemento de lo maravilloso que, paradójicamente, racionalizaba sus juicios. Pero, incluso, esta afirmación permite entender que tampoco pudo adscribir a los habitantes del territorio que estaban ocupando, aquellos aspectos relacionados al campo de las ideas y de la organización socio-política, que también lo dejaron perplejo. En este caso encontramos a un perceptor que se esfuerza por aplicar categorías no pertinentes al objeto que observa, relacionándolo con experiencias que le permitieran justificarlo porque no podía vincularlo, obviando la razón definitivamente política que debió orientar su narración, con el pueblo productor. No era capaz de reconocer la crea- 
ción de los sujetos productores, ni siquiera se planteó la posibilidad de comprender. Es interesante su postura porque este observador español no se muestra en general reacio a admitir el valor de lo que ve. Sin embargo, este pasaje de la primera parte de la Crónica de Cieza de León reviste importancia por dejar en evidencia que la condición, interés y función del narrador cuando describía sus experiencias, le suponía encontrar una explicación que negara al pueblo nativo la capacidad de su realización. Incluso es más importante esta postura si se recuerda que Cieza de León llegó relativamente tarde al Perú, lo suficiente como para no encontrar monumentos íntegros, porque sus predecesores los habían saqueado y destruido desde el primer año de su estadía, por tanto no tuvo la oportunidad de verlos completos y en uso. Su opinión podría haber sido más radical. Pero, y no se tratará en extenso este asunto, también se desprende del párrafo citado que las comunidades fueron hábiles evaluadoras de la condición del invasor. Los cronistas de la segunda mitad del siglo XVI pudieron advertir, directa o indirectamente, que los testimonios que recibían de los indígenas, así como los usos y costumbres que parecieron asimilar, reflejaban la aspiración del europeo antes que la condición real que pretendían (Barriga 2003).

Los cronistas en gran parte orientaron sus descripciones con ánimo de exculpación, amparándose en descripciones dirigidas o en testimonios condicionados. Esta posición se encuentra más clara en un texto de inicios del XVII. Bernabé Cobo, a propósito del sistema de contabilidad peruano, afirmó

y es cosa digna de advertir, que siendo todas las cosas de los indios tan diferentes a las nuestras, en las especies de los números y manera de contar conformen tanto así los peruanos como los mejicanos, que no haya entre nosotros y ellos ninguna diferencia. Lo cual no sé yo a qué atribuirlo sino a que las gentes que a poblar este Nuevo Mundo vinieron, debieron de guardar el modo de contar que aprendieron en el Mundo Viejo, de donde salieron, y ser aquél el mismo que nosotros y ellos hemos conservado (Cobo 1956: Libro 12, Cap. XXXVII).

De la lectura de los documentos iniciales se extrae que la primera lectura visual europea de la realidad sudamericana estuvo signada por las experiencias previas, tanto como de la expectativa respecto a lo que se había difundido en la zona americana ocupada anteriormente. Fue central la condición del narrador que describe. Primó la construcción 
mental elaborada en los largos días de travesía, acrecentada por los rumores y las aspiraciones. No se identifica lo que se observa de manera objetiva, sino que la descripción e interpretación se ajustan a lo que se concibe previamente que debe encontrarse, a una forma representativa previamente elaborada y fijada. La solución que supone emplear un término conocido para describir o denominar aquello que escapa a la experiencia, implica también establecer un nexo entre la interpretación del objeto nuevo con otro de diferente contexto al que se le vincula. El objeto pasa a engrosar el concepto que ya tiene delimitado otro, con una connotación precisa en la mente del receptor. El mecanismo es útil tanto para denostar como para enaltecer. Debe considerarse que las crónicas, memoriales y relaciones tienen la intención de convencer al receptor ideal, la autoridad peninsular, de la riqueza y, por tanto, de la importancia significativa de los hallazgos para los intereses de la nación. La mirada hispana apunta a destacar lo visto y a minimizar los efectos negativos sobre sus acciones que hubiese supuesto reconocer a los propietarios de la riqueza. En última instancia, su objetivo es sobre dimensionar la campaña para elevar el valor de los protagonistas. Adicional a ello también debe justificarse la ocupación. El pueblo encontrado no tenía una cultura superior, no era responsable de su magnitud porque "otra raza", similar a la europea, había dejado el legado que los asombraba. Es por ello que las crónicas iniciales, salvo que se confronten minuciosamente, sirven poco para recomponer la condición del Tawantinsuyo en el momento que tratan. Son reconstrucciones en las que la intervención del sujeto y su circunstancia fueron determinantes. Como consecuencia, la interpretación minusválida de la condición del americano, que usufructuaba una realidad que lo sobrepasaba, quedó fijada en el siglo XVI (Barriga Tello 2003: 77-78). Primero en la percepción que los primeros españoles tuvieron de las civilizaciones nativas y, posteriormente y por extensión, en la manera en que la península consideró a los españoles americanos y sus productos culturales. La reacción de los pueblos fue de permanente lucha por el reconocimiento al que tenían derecho, como dueños de la tierra los unos, y como creadores emuladores de un poder lejano y ajeno los otros. 


\section{Referencias bibliográfícas}

BARRIGA TELLO, Martha (2003). El arte en el origen de un desencuentro: Dos Imperios en el Perú del siglo XVI. Patio de Letras, Año 1, No 1, Lima: (71-79).

CIEZA de LEÓN, Pedro (1989). Crónica del Perú III. Lima: Fondo Editorial de la Pontificia Universidad Católica del Perú

CIEZA DE LEÓN, Pedro (1947). Crónica del Perú I. Madrid: Biblioteca de Autores Españoles, Tomo XXVII.

COBO, Bernabé (1956). Historia del Nuevo Mundo. Madrid: Biblioteca de Autores Españoles.

ENRÍQUEZ de Guzmán, Alonso (1960). Libro de la vida y costumbres de ... caballero desbaratado, escrito por él mismo. Madrid: Biblioteca de Autores Españoles, Tomo 126.

ESPINOZA, Gaspar de (1967). "Carta desde Panamá”. En: Raúl Porras B. Las relaciones primitivas de la conquista del Perú. pp. 38-41.

ESTETE, Miguel de (1968). Noticias del Perú de ... Lima: Editores Técnicos Asociados (ETA), Biblioteca Peruana I.

GASCA, Pedro de la. Descripción del Perú (1551-1553). Cusco: Centro de Estudios Regionales Andinos Bartolomé de las Casas, 1998.

JEREZ, Francisco de (1968). Verdadera relación de la conquista del Perú y la provincia del Cuzco llamada Nueva Castilla. Lima: Editores Técnicos Asociados (ETA), Biblioteca Peruana I.

RELACIÓN Xámano - Jeréz 1533. En: PORRAS BARRENECHEA, Raúl, 1967 (63-68) .

MENA, Cristóbal de (1967). "La conquista del Perú llamada Nueva Castilla”. En: PORRAS BARRENECHEA, Raúl. (79-102).

PIZARRO, Hernando (1968). Carta. Lima: Editores Técnicos Asociados (ETA), Biblioteca Peruana I, pp. 119-130. 
PORRAS BARRENECHEA, Raúl (1967). Relaciones primitivas de la conquista del Perú. Lima: Instituto Raúl Porras Barrenechea, Universidad Nacional Mayor de San Marcos.

SANCHO, Pedro (1968). Relación para su Majestad. Lima: Editores Técnicos Asociados, Biblioteca Peruana, I.

VARGAS UGARTE, Rubén (1981). Historia general del Perú, I. Lima: Editorial Carlos Milla Batres. 